Para enlazar con este artículo / To link to this article:

http://dx.doi.org/10.14198/fem.2018.32.03

Para citar este artículo / To cite this article:

Navarro Martínez, Héctor y García-Badell Delibes, Guillermo. «Mecenazgo en femenino. La reivindicación sostenible a través del encargo arquitectónico». En Feminismo/s, 32 (diciembre 2018): 65-99. Dosier monográfico: MAS-MES: Mujeres, Arquitectura y Sostenibilidad - Medioambiental, Económica y Social, coord. María-Elia Gutiérrez-Mozo, DOI: 10.14198/fem.2018.32.03

\title{
MECENAZGO EN FEMENINO \\ LA REIVINDICACIÓN SOSTENIBLE A TRAVÉS DEL ENCARGO ARQUITECTÓNICO
}

\author{
FEMALE PATRONAGE \\ THE SUSTAINABLE CLAIM THROUGH \\ THE ARCHITECTURAL COMMISSION
}

\author{
Héctor NAVARRO MARTÍNEZ \\ Universidad Politécnica de Madrid \\ hectornavarro@me.com \\ orcid.org/0000-0002-7692-7836 \\ Guillermo GARCÍA-BADELL DELIBES \\ Universidad Politécnica de Madrid \\ guillermo.garciabadell@upm.es \\ orcid.org/0000-0002-3990-2744
}

\section{Resumen}

El presente texto tiene como objetivo analizar el mecenazgo promovido por mujeres dentro del ámbito de la arquitectura, subrayando la importancia que las promotoras han tenido en la esfera residencial. Se han seleccionado los casos de estudio de tres mujeres: Truss Schröder, Edith Farnsworth y Manorama Sarabhai. A través de sus experiencias con los arquitectos que contrataron, Gerrit Rietveld, Mies van der Rohe y Le Corbusier respectivamente, se analizarán las tres viviendas. En todos los ejemplos seleccionados hubo una intensa relación profesional entre cliente y arquitecto, y la relevancia de las propuestas desarrolladas consiguió elevar el papel clientelar al de mecenas. Mediante un análisis comparativo desde una perspectiva de género, se destacarán los significados implícitos de unas propuestas que superan consideraciones

Los contenidos de la revista se publican bajo una licencia de Creative Commons Reconocimiento 4.0 Internacional (CC BY 4.0)

Feminismo/s 32, diciembre 2018, pp. 65-99 
arquitectónicas-espaciales para subrayar cómo gracias a la visión de las mencionadas mujeres se promueve una sostenibilidad aplicada a la arquitectura que puede ser medioambiental, económica y social.

Palabras clave: mecenazgo, encargo arquitectónico, Truss Schröder, Edith Farnsworth, Manorama Sarabhai

\begin{abstract}
The purpose of this text is to analyse the patronage promoted by women in the field of architecture, underlining the importance of these actions in the residential sphere. Three study cases have been selected; Truss Schröder, Edith Farnsworth and Manorama Sarabhai. Through their experiences with the architects they hired, Gerrit Rietveld, Mies van der Rohe and Le Corbusier respectively, three houses will be analysed. In all of them there was an intense professional relationship between client and architect, and the relevance of the developed proposals turned their role as clients into patronage. Through a comparative analysis from a gender perspective, the implicit meanings of proposals that go beyond spatial architectural considerations will be highlighted to underline how, thanks to the vision of these women, a sustainability applied to architecture can be promoted, which can be environmental, economic or social.
\end{abstract}

Keywords: Patronage, architectural commission, Truss Schröder, Edith Farnsworth, Manorama Sarabhai

\title{
1. INTRODUCCIÓN
}

Desde que se iniciasen los estudios referidos a las contribuciones de las mujeres en la historia de la arquitectura, esta revisión necesita atender a los complejos mecanismos en los cuales lo cultural y la ideología subyacen como parte de cualquier manifestación arquitectónica. Más allá de los trabajos realizados por mujeres, que en muchos casos habían sido negados o suprimidos de los libros de historia, es importante enfatizar cómo trabajos de investigación interdisciplinares desarrollados durante los últimos años, amplían el radio de acción tratando estos temas desde una perspectiva de género. Inés Moisset indaga en este aspecto, recolectando los datos porcentuales de publicaciones referidas a mujeres arquitectas, bibliografías específicas, incluso en medios virtuales de la actualidad: «Wikipedia repite los estereotipos de género existentes en la producción académica»(20). Otros trabajos de investigación,

Feminismo/s 32, diciembre 2018, pp. 65-99 
La reivindicación sostenible a través del encargo arquitectónico

como los desarrollados por Patricia Santos Pedrosa, suponen una aportación relevante, reescribiendo fragmentos de la historia de la arquitectura desde una perspectiva de género y atendiendo a la especificidad de un contexto determinado, en este caso el portugués. Las soluciones arquitectónicas no sólo responden a concesiones estéticas y criterios formales, sino también a temas culturales que pueden ser desmenuzados desde una visión antropológica en la que se incluyen otras variables implicadas, como la organización social, la ideología de género, el gusto o las relaciones entre personas dentro de una comunidad. No sólo eso, sino modelos de vida, sexualidad o raza también van a ser determinantes en esta nueva visión.

Partiendo de la base de que la norma viene definida por las necesidades estipuladas por «el hombre blanco heterosexual», es imprescindible atender a otros casos que se salen del marco establecido. Es decir, formas de vida tradicionalmente consideradas «no convencionales» que suponen un nuevo reto para el arquitecto responsable. Casos paradigmáticos como el apartamento del arquitecto Paul Rudolph diseñado como vivienda propia para él y su pareja masculina, o la Glass House de Philip Johnson, ofrecen casos de estudio donde lo masculino y lo femenino pasan a un segundo plano y, en cambio, las cuestiones de género y la sexualidad ponen de relieve la no adecuación de los espacios domésticos tradicionales a otras estructuras de convivencia. Friedman ha ahondado en estos temas subrayando cómo «la relación entre arquitectura y representación se extiende a convenciones y valores relacionados con la orientación sexual, así como a otros factores como la estructura familiar, la organización del hogar o el estatus marital» (Your place or mine? 72).

Los casos seleccionados deben ser entendidos desde una perspectiva más amplia. Y, al tratar la importancia de las mujeres en la historia de la arquitectura, no sólo se debe recuperar su trabajo como diseñadoras, sino también como promotoras a la cabeza de los proyectos de edificación; las mujeres como clientes en toda su diversidad sustituyendo la figura masculina. Pueden ser casadas, solteras o viudas, con o sin hijos, heterosexuales u homosexuales... En definitiva, los distintos casos representan modelos de familia que se salen de las normas establecidas en cuanto al concepto canónico de familia, modelos en los que se entiende que la mujer no es un estereotipo estricto, sino que se acepta en su heterogeneidad. En ese sentido, el presente artículo

Feminismo/s 32, diciembre 2018, pp. 65-99 
viene referido a tres casos de estudio: la casa Schröder, la casa Farnsworth y la casa Sarabhai, tres obras radicales e imprescindibles del siglo XX diseñadas por Gerrit Rietveld, Mies van der Rohe y Le Corbusier respectivamente. Todos ellos ejemplos de arquitectura residencial que desafiaron los modelos consolidados de vivienda tradicional no sólo en cuanto a su solución espacial-formal y técnica, sino también a su concepción más básica como espacio dedicado a acoger las relaciones humanas dentro del núcleo familiar. Y tres mujeres clientes -Truss Schröder, Edith Farnsworth y Manorama Sarabhai- son la otra cara de la moneda que forma parte de estos procesos creativos, en los cuales su visión del mundo, sus necesidades y requisitos inusuales fueron responsables de nuevas e innovadoras soluciones. Las viviendas que construyeron para sí mismas trascendieron lo personal y se convirtieron en proyectos de mayor alcance elevando su papel al de mecenas del Movimiento Moderno.

Cynthia Lawrence, que ha escrito sobre el mecenazgo femenino, destaca la necesidad de que se den tres factores para que el mecenazgo ocurra: riqueza, libertad e influencia (4). En muchas ocasiones, estos factores llevan asociados modos de vida que se salen de la norma y a través de cualquier manifestación artística se define toda una declaración personal. Otras autoras como Victoria Combalía han estudiado el mismo asunto desde el ámbito del arte, en el cual, en muchas ocasiones, la frontera entre la figura de mecenas y musa resulta difusa. Combalía incide en aquellas que toman un papel híbrido entre una figura y otra, destacando el abandono de la pasividad, atributo históricamente asociado al concepto de musa y diametralmente opuesto al de genio, siempre hombre, entendido como elemento activo en el proceso de creación.

\subsection{Cuestiones de género en la arquitectura doméstica}

Muchas de las soluciones adoptadas interesa que sean analizadas en clave antropológica, donde espacio y género implican una concepción semiótica de la propia arquitectura. Cualquier proyecto de vivienda contiene una configuración espacial de carácter funcional cuya última intención es su ocupación y habitabilidad. Sin embargo, en el análisis de las soluciones arquitectónicas detalladas en este texto se trasciende el plano utilitario para entrar a considerar el sistema semiótico, de modo que dichas soluciones adquieren una dimensión simbólico-cultural.

Feminismo/s 32, diciembre 2018, pp. 65-99 
La reivindicación sostenible a través del encargo arquitectónico

En los casos seleccionados, se tiene la oportunidad de incluir como base de trabajo la intrahistoria del proyecto; algunas experiencias entre cliente y arquitecto están ampliamente documentadas, mientras que otras parten de una información discreta sobre los personajes implicados. Así y todo, en un caso y otro, una lectura pertinente permite identificar el peso del constructo cultural de la época, la personalidad de la mujer en cuestión y lo que ocurre cuando es ella quien forma parte del tándem responsable de idear un espacio concebido como vivienda.

Roland Barthes definía cómo cualquier intención funcional se transforma en signo cuando este adquiere un carácter social (30). De lo que se puede deducir que, desde una perspectiva arquitectónica, cualquier expresión de esta contiene códigos que permiten hacer una lectura y posterior interpretación. Entre las muchas variables que inciden en la creación arquitectónica está lo material, lo técnico o lo económico, así como la dimensión imaginativa y ejecutora, todas ellas dependientes de un contexto concreto circunscrito a unos determinantes socioculturales.

La lectura de los distintos proyectos se va a apoyar en un discurso sintáctico de clasificaciones binarias basadas en dicotomías como arriba-abajo, dentro-fuera, cerca-lejos o cerrado-abierto. Aspectos universales acometidos desde la antropología estructural que van a permitir acceder a un plano temático muy elemental donde gran parte del discurso implícito no puede ser obviado. Este asunto es desarrollado por Francisco Sánchez Pérez en su obra La liturgia del espacio, quien completa el análisis apoyándose en dos disciplinas más: la proxémica y la kinésica (12). La kinésica hace referencia a los significados relativos al lenguaje corporal, y la proxémica, desarrollada por Edward T. Hall, está centrada en la comprensión de los significados que subyacen en la relación entre las personas y el espacio en diferentes contextos culturales.

Sánchez Pérez define grosso modo que el interior de la vivienda está asociado a lo femenino mientras que el exterior pertenece a la dimensión masculina, correspondencia que no es totalmente rígida y varía a lo largo del día. A partir de una noción basada en lo interior-exterior, masculino-femenino o el concepto de intimidad, se incluyen significados relativos a nociones de liminalidad entre esferas definidas por pares dicotómicos (61). Es precisamente en la vivienda donde se enfatiza esa distinción entre lo público y lo privado.

Feminismo/s 32, diciembre 2018, pp. 65-99 
La reivindicación sostenible a través del encargo arquitectónico

Desde el interior, su asociación a la intimidad y una subjetiva libertad se han definido los roles asignados a cada género.

La vivienda occidental refleja la subordinación femenina, creando un sistema espacial codificado. Caballero Galván sostiene que «esta estructura (espacial) tendrá además como objetivo desactivar por completo la capacidad de las mujeres para subvertir este orden y velar el sentido político que toda estructura espacio-objetual porta por el hecho de estar significada a través de las relaciones sociales» (39). Por lo tanto, cualquier acción que desafíe las estructuras espaciales heredadas, supondrá un gran avance para acometer la redefinición del rol de la mujer en la sociedad.

Así que la resignificación y reconfiguración del espacio se pondrá en marcha en principio con la parcelación de la ciudad: la calle se convertirá en el territorio de lo público, en el espacio del reconocimiento, de lo visible, de lo abierto: de lo masculino, mientras que la vivienda se irá convirtiendo en el espacio de las mujeres, en el espacio de lo íntimo, de lo cerrado, de lo no visible; espacio en el que se realiza la sexualidad, el sueño, la enfermedad y la muerte. Y será en este donde la intimidad quedará significada de forma diferente para cada género, pues si bien el desarrollo del sujeto escindido ha sido la base sobre la que se ha edificado el marco de sentido burgués que actualmente codifica el mundo, no representará lo mismo para hombres que para mujeres (Caballero Galván 41).

La intimidad del hombre es una reclusión momentánea, necesaria para descansar de la constante interacción pública. Mientras que, para las mujeres, esa intimidad es una condición inherente a su identidad. La estancia femenina en la esfera pública tiene un carácter transitorio y efímero que en muchas ocasiones es la extensión de las actividades que las mujeres realizan en el espacio interior. (Del Valle 231). Si se hace una traslación espacial, ese par dicotómico interior-exterior también se da en las subdivisiones de espacios propios de la vivienda y la mujer siempre aparece despojada de un espacio propio.

Todas estas consideraciones permiten un mejor entendimiento del rol de la mujer dentro del ámbito doméstico y una toma de consciencia de los significados implícitos que contienen las soluciones espaciales y materiales de los sistemas espaciales heredados de la casa burguesa. Estas consideraciones se incluirán en el análisis de las propuestas ideadas por las clientes seleccionadas y sus arquitectos, facilitando su relectura desde una perspectiva de género, en donde gracias a sus demandas y concepciones más generales sobre

Feminismo/s 32, diciembre 2018, pp. 65-99 
La reivindicación sostenible a través del encargo arquitectónico

sí mismas consiguen deshacer los referidos pares dicotómicos y su asignación de género implícita.

\section{TRES MUJERES: TRUSS, EDITH Y MANORAMA}

En lugar de plantearse como casos de estudio diferenciados, interesa hacer un análisis comparado que permita identificar denominadores comunes. A través de las biografías de Truss Schröder, Edith Farnsworth y Manorama Sarabhai, será posible contextualizar sus «mapas mentales» e intereses, lo que ayudará a comprender los significados que subyacen en las propuestas espaciales desarrolladas por sus arquitectos.

Truss Schröder era una joven viuda cuando se mudó junto a sus tres hijos a la casa diseñada por Gerrit Rietveld. Un proyecto desarrollado por dos personas con una visión clara sobre los objetivos a cumplir. Para Rietveld, este era el primer proyecto que construiría (previamente había diseñado mobiliario y había hecho trabajos de interiorismo) y para Truss Schröder esta colaboración debía conseguir dar forma a un espacio capaz de acoger un modo de vida en familia muy determinado que ella tenía en mente (Badovici $\left.{ }^{1} 29\right)$.

Truss Schröder procedía de una familia de clase media-alta. Aunque tuvo una formación como farmacéutica, realmente nunca llegó a ejercer como tal. En cambio, se interesó por el arte, la literatura, la filosofía y la arquitectura, incluso llegando a tomar algunos cursos en la Universidad Técnica de Hannover (García García 26). Su hermana Ann, escritora y crítica de arte, fue la responsable de introducirla en círculos vanguardistas dando forma a una visión del mundo muy centrada en la educación de sus hijos. Quería aplicar la teoría leída en los libros, lo que le permitiría educar a sus vástagos para ser unas mejores personas con una mirada del mundo mucho más coherente dentro de la sociedad en la que les había tocado vivir. Gracias a Harrentstein-Scharäder, escritor y crítico de arte, Truss conoció a la élite de artistas del movimiento De Stijl, así como a otras personalidades como Theo van Doesburg, Bruno Taut o Kurt Schwitters entre otros (Friedman, Women and the Making 71). Estas relaciones supusieron un estímulo intelectual que le hizo educar su mirada sobre el espacio y sus significados implícitos. La

1. Jean Badovici subrayó la contribución de Schröder, llegando a nombrarla junto a Rietveld como coautora.

Feminismo/s 32, diciembre 2018, pp. 65-99 
primera relación profesional entre Truss y Gerrit fue mediada por su marido Frits Schröder tras conocer la reforma para la joyería GZC de Ámsterdam, realizada por Rielveld (García García 8). Esa primera experiencia profesional consistió en diseñar una habitación existente dentro de la vivienda del matrimonio, un espacio propio, confortable y capaz de funcionar como un interfaz más adecuado a su visión del mundo. De alguna manera, fue en dicha habitación donde comenzó la relación entre arquitecto y cliente, donde debatían sobre su visión del mundo, sus relaciones personales con este o el significado del arte (Friedman, Women and the Making 73). Y también se convirtió en la carta de presentación para Rietveld con las visitas de figuras como Taut o El Lissitzsky (García García 8).

Aunque Rietveld tenía mujer y seis hijos en Utrecht, esto no le impidió iniciar una relación más allá de lo profesional con Truss, amante además de amiga (Friedman, Women and the Making 69). De hecho, entre 1924 y 1932 Rietveld mantuvo una pequeña oficina en la casa y cuando falleció su mujer en 1958, se mudó a la vivienda hasta su muerte en 1985. Con la ausencia de los hijos una vez independizados, se alteró la distribución para que pudiese vivir en la primera planta. Más tarde se restituyó su estado original de 1924 (Rietveld et al. 53).

El proyecto de vivienda se convirtió por lo tanto en una oportunidad para crear una propuesta moderna libre de las tradiciones y reglas, tanto arquitectónicas como sociales, que regían la arquitectura doméstica. De hecho, esta primera experiencia terminó creando una alianza profesional para futuros proyectos durante la década de los años 20 (Friedman, Women and the Making 66).

En el caso descrito, el vínculo entre arquitecto y cliente era muy estrecho. Algo similar a la relación entre Mies van der Rohe y Edith Farnsworth (1903-1977), que también fueron íntimos amigos, aunque su relación acabó empeorando hasta llegar a los tribunales. Edith era una doctora soltera de Chicago que a sus cuarenta años empezó a concebir la idea de construirse una pequeña vivienda para los fines de semana, alejada de la ciudad.

En 1945, Edith conoció a Mies van der Rohe y, tal y como se puede entender en sus memorias, el inicio de su relación era la típica entre un arquitecto y cliente, donde Edith esperaba de su arquitecto que fuese capaz de dar respuesta a sus necesidades con una vivienda de cuidado diseño. Sin embargo,

Feminismo/s 32, diciembre 2018, pp. 65-99 
La reivindicación sostenible a través del encargo arquitectónico

Edith pronto fue consciente de que lo que veía Mies en ella era una mecenas, cuyo dinero convertiría en realidad los sueños y ambiciones del arquitecto. Como es lógico, detrás de una obra como la casa Farnsworth cabe presumir la existencia de un cliente a la altura. Edith era una mujer cultivada gracias a sus viajes por Europa y con unos intereses saciados a través de la lectura. Había aprendido música y ella misma se interesó por lecturas de aquello que había alimentado el discurso de Mies. Por ejemplo, leyó los escritos de Romano Guardini con intención de acercarse a temas de radical interés para Mies, como era el concepto de liturgia en la arquitectura (Friedman, Women and the Making 134).

Las visitas a la parcela los fines de semana y su intensa relación donde los límites entre cliente-arquitecto y amigos eran cada vez más difusos, hicieron presuponer una relación sentimental entre ellos, aunque en ningún texto ella reconoció ninguna relación con Mies van der Rohe (Friedman, Women and the Making 133). Lo que está claro es que, a diferencia del siguiente caso, Le Corbusier y Manorama Sarabhai, había una relación continuada y cercana entre ellos.

Las diferencias entre Schröder y Farnsworth son ya, a este nivel, bastante claras. Aunque Truss Schröder parece que fue consciente desde el inicio de su intención de crear una pieza de arquitectura relevante que cumpliese funciones más allá de las preestablecidas, en el caso de Edith esta postura tuvo numerosos altibajos. Es decir, Truss fue plenamente consciente y activa en la definición de un proyecto de vivienda moderna, una postura que de manera implícita la elevaba a la figura de mecenas. Esto no fue así en el caso de Edith Farnsworth, cuya tentativa inicial era la de simplemente involucrarse en la definición del proyecto desde su posición como cliente. Sin embargo, un gran hito en la redefinición de su rol como mecenas fue la exposición de la maqueta de la casa Farnsworth en la exposición comisariada por Philip Johnson en el MOMA en 1947 (figura 1). Su protagonismo contagió de orgullo a una cliente que tomaba conciencia de su papel como mecenas, donde las fronteras entre sus propios intereses y el entusiasmo por formar parte de un proyecto intelectual de mayor alcance cada vez adquiría más peso. De hecho, parece que gran parte de los problemas que más tarde surgirían entre ella y el arquitecto se debieron a las habilidades de Mies por no ser totalmente claro con la propuesta. Por ejemplo, en la citada maqueta las fachadas aparecían translúcidas

Feminismo/s 32, diciembre 2018, pp. 65-99 


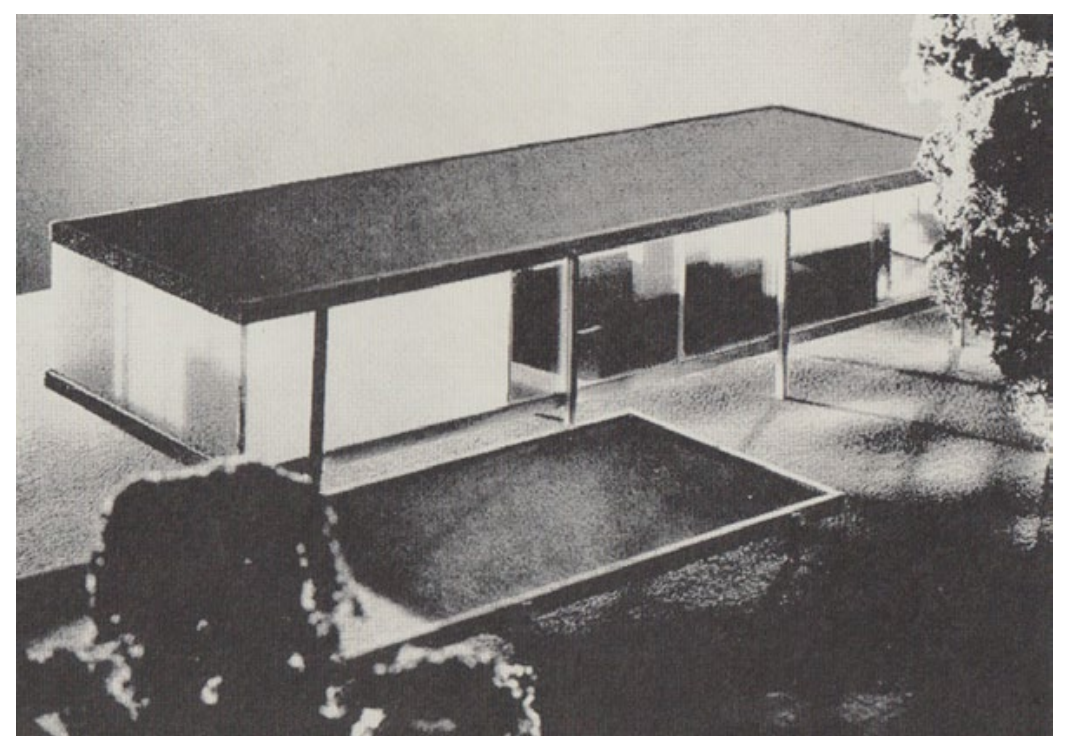

Figura 1.

en dormitorio y cocina, lo que hace suponer que Mies era consciente de aquellas cuestiones que estaba introduciendo y podrían ser rechazadas por su cliente y futura inquilina. Así todo, distintos autores se cuestionan cómo fue posible que Edith no fuese consciente de la propuesta hasta el final del proceso (Vandenberg 15). En cualquier caso, Mies mantuvo una postura que velaba por sus propios intereses como arquitecto comprometiendo las necesidades reales de la Señora Farnsworth.

En el caso de Edith, esa influencia e intención de elevar su papel como mecenas parecen provenir de estímulos exteriores más que de una convicción propia. De alguna manera, analizando los hechos que se sucedieron durante la construcción de la vivienda, se podría entender que era víctima de su contexto y a veces, resultaba harto complicado obviarlo.

La arquitectura doméstica americana de los años 40 y 50 representa unos ideales donde las áreas suburbanas organizaban vastas extensiones de urbanizaciones con viviendas para familias ideales. Libros como Common Sense Book of Baby and Child Care de Benjamin Spock (1946) modelaron la vida de las mujeres de la época cuya ocupación como madres suponía una

Feminismo/s 32, diciembre 2018, pp. 65-99 
La reivindicación sostenible a través del encargo arquitectónico

dedicación a tiempo completo (Gray 1998 108). Las personas que no tenían hijos, sobre todo mujeres, eran vistas con condescendencia por la sociedad. Automáticamente se les atribuía algún tipo de inestabilidad o se presuponía una condición homosexual. Por lo tanto, el concepto de hogar de la sociedad norteamericana de la época estaba irremediablemente vinculado al de familia monoparental.

Para cuando comienza la construcción de la casa Farnsworth en 1949, la relación entre cliente y arquitecto se había enfriado. Sin embargo, el conflicto entre ambas figuras no deja de ser una situación que se ha dado en multitud de casos donde variables como el poder, el dinero o quién está bajo control forman parte de las dinámicas del proyecto. De alguna manera, y más en un proyecto de arquitectura residencial, existen unos supuestos sobre cómo hombres y mujeres viven sus vidas, lo cual da forma a los requisitos explícitos e implícitos del programa del edificio. De hecho, cuando entran en juego modos de vida inusuales, esto puede suponer puntos de desencuentro entre las partes.

Aunque se entiende que las primeras fricciones fueron evidentes a través de un distanciamiento, en diciembre de 1950, para cuando Edith se había mudado, los problemas de la vivienda acrecentaron las tiranteces. Se tuvo que rehacer la instalación eléctrica, hubo problemas en la cubierta y condensaciones en ventanas, además del conflicto derivado del presupuesto. El precio final duplicaba el presupuesto estimado y, más tarde, Mies solicitó unos honorarios extra. El arquitecto incluso pretendió diseñar el mobiliario, a lo cual se opuso Edith. Para la primavera de 1951 ya ni siquiera se hablaban y el tema pasó a manos de sus abogados lo que prolongó la batalla judicial hasta mayo de 1956 tras lo cual Edith tuvo que realizar un pago inferior al exigido por el arquitecto (Fernández Salas 7).

La prensa se sumó a este episodio de la historia de la arquitectura y la atención mediática provocó que los curiosos acudiesen los fines de semana a ver la casa desde el exterior. El asunto se convirtió en una crítica hacia la arquitectura moderna donde se ridiculizaba lo absurdo de pagar 70.000 dólares por una vivienda de un dormitorio sin intimidad alguna y deficiencias técnicas. No sólo eso, sino que el tema trascendió y la casa empezó a ser entendida como una expresión del totalitarismo importado desde Alemania con intención de definir cómo debía ser el modo de vida americano (Castillo 10). Tampoco ayudaron las entrevistas concedidas por Edith criticando cómo

Feminismo/s 32, diciembre 2018, pp. 65-99 
La reivindicación sostenible a través del encargo arquitectónico

ese «espacio libre», al que tanto aludía Mies, en verdad suponía una esclavitud para su inquilino. La excesiva sobrexposición implicaba una rectitud desmesurada en términos de limpieza y el simple hecho de incorporar un mueble suponía un problema en un espacio tan medido por el arquitecto (Friedman, Women and the Making 132). En ese sentido, resulta interesante volver a citar a Sánchez Pérez, quien subrayaba en su análisis antropológico del espacio doméstico la variable de la limpieza. Esta actividad diaria es imprescindible que se dé para que la casa pueda recibir personas ajenas a la vivienda, forma parte del ritual diario. En este caso, la cocina de la casa Farnsworth está completamente expuesta. Durante su uso, de espaldas al exterior, la escena se convierte en una especie de altar de uno de los elementos más imprescindibles del modo de vida americano. En una entrevista recogida por Friedman, Farnsworth se expresa en ese sentido. «¿Qué más? No guardo basura debajo de mi fregadero. ¿Sabes por qué? Porque puedes ver toda la 'cocina' desde la carretera y una lata estropearía la apariencia de toda la casa» (Friedman, Women and the Making 141).

Es interesante analizar cómo el papel del mecenas, sujeto a una variable funcional, hace que la intencionalidad quede sujeta a necesidades vinculadas con lo personal. De alguna manera, el mecenazgo en arquitectura, sobre todo si se trata de arquitectura residencial, está sujeto a una variable funcional directamente vinculada al cliente, que en última instancia va a sufrir o disfrutar en primera persona la obra en la que ha invertido su tiempo y dinero.

El tercer ejemplo seleccionado, el proyecto de la casa Sarabhai, se inicia tras la muerte del marido de Manorama Sarabhai, hijo de Seth Ambalal Sarabhai ${ }^{2}$. El patriarca había cedido una parte de su finca a cada uno de sus hijos facilitando su emancipación y sin hacer excepción ocurrió lo mismo con Manorama Sarabhai, quien viviría con sus dos hijos, Sufrid y Anand, de diez y trece años respectivamente (García González, Mas Llores y Santatecla Fayos 2).

En el caso de la Señora Sarabhai, el programa de la vivienda fue definido con una intensa discusión en persona y a través de cartas partiendo de

2. Seth Ambalal Sarabhai era uno de los hombres más influyentes de la ciudad. Había consolidado la gran empresa algodonera de su familia, además de haber sido presidente de la Asociación de Hilanderos y miembro del equipo municipal de Ahmedabad.

Feminismo/s 32, diciembre 2018, pp. 65-99 
La reivindicación sostenible a través del encargo arquitectónico

las precisas necesidades definidas por ella misma. Hay que tener en cuenta que, aunque Le Corbusier estaba inmerso en el diseño de varias obras en India, su oficina base estaba en París. Tanto su cuñada Gira como su cuñado Gautam ayudaron en este proceso, viajando incluso a Europa para visitar algunos proyectos de Le Corbusier. De hecho, Gira había estudiado con Frank Lloyd Wright y era conocedora de la arquitectura contemporánea en Europa y América. Además de ayudar a solucionar distintas crisis, estas acciones fueron respaldadas pues eran conscientes de la trascendencia histórico-artística de un proyecto de la mano Le Corbusier (Curtis 210). Por lo tanto, una vez más se puede observar esa toma de consciencia sobre el mecenazgo en activo que se estaba realizando más allá del papel clientelar. El compromiso de Manorama también se puede evidenciar teniendo en cuenta que al final del proceso de diseño, ella misma consultó diversos temas con Jean Louis Véret, arquitecto incluido en el equipo responsable del proyecto junto a Doshi, y escribía con frecuencia a Le Corbusier expresando sus dudas sobre diversos temas y conflictos que percibía en el diseño. Es importante subrayar cómo en el caso de Le Corbusier, hubo mujeres clientes en numerosos proyectos. Como apunta Flora Samuel: «Le Corbusier era plenamente consciente de la creciente fortaleza económica de las mujeres. De hecho, parece haber buscado su atención, entendiendo que eran más receptivas a sus ideas» (30).

Además de su activo papel y el asesoramiento de sus cuñados, también estuvieron presentes en el proceso creativo sus hijos. Tal y como explica uno de ellos en el documental Le Corbusier en la India. Ahmedabad y Chandigarh (2000), los hermanos habían leído unos cuentos en donde los protagonistas vivían en unos cubos de los que salían a través de un tobogán por el que se deslizaban al exterior. Era tal su fascinación con este cuento, que se lo llegaron a mostrar al arquitecto suizo en una de sus visitas a los jardines. Le Corbusier quedó encantado con la idea y la desarrolló. Ese artilugio al que se refieren aparecía en el cuento Fattypuffs and Thinifers, obra de André Maurois, algo parecido a un tobogán-reloj-despertador que lanzaba a los personajes desde la cama hasta la bañera.

Una de las premisas definida por Sarabahi era precisamente que debía haber un respeto absoluto al entorno natural circundante. Generalmente, se atribuye el respeto medioambiental de los proyectos de Le Corbusier en India a la propia sensibilidad del arquitecto, en este caso conviene entonces

Feminismo/s 32, diciembre 2018, pp. 65-99 
La reivindicación sostenible a través del encargo arquitectónico

recordar el mérito que en este sentido tiene su cliente. Una descripción que puede ayudar a definir el perfil de la cliente es el dado por William Curtis «La señora Sarabhai era el tipo de cliente india que tenía gallinas y vacas en el jardín, pero también poseía el coche Chrysler de último modelo» (210).

En los tres casos, los proyectos no son sólo «hijos» de su arquitecto, sino que las soluciones empleadas están tremendamente condicionadas por sus clientes, tres mujeres con circunstancias muy distintas, pero todas muy involucradas en el diseño de sus casas. Truss Schröder toma la iniciativa y junto a Rietveld definen la propuesta con un importante acuerdo y acierto. Edith Fansworth también resulta imprescindible por el programa que se desprendía de sus necesidades e inicial entendimiento con el arquitecto, aunque parece que en este caso el peso recayó en Mies y la solución no fue tan consensuada como en el caso anterior. En cambio, Manorama es la protagonista de un grupo de personas pertenecientes a la familia involucrado en el asesoramiento y toma de decisiones, siendo en todo momento conscientes de su papel como mecenas. ${ }^{3}$ Aunque por supuesto es Le Corbusier quien define las pautas del proyecto en un excelente momento de madurez de su carrera. En cualquier caso, las tres viviendas destacadas pautan las variables de innovación y las clientes están completamente involucradas en el proceso creativo. Por su cuenta o asesoradas, sus demandas, su visión del mundo y la confianza depositada en el arquitecto dieron como resultado proyectos sobresalientes en la historia de la arquitectura. Tanto Truss Schröder como Manorama Sarabhai tuvieron muy presentes a sus hijos en el proceso de diseño. La primera tomó como base argumental la educación de sus hijos para dar forma al concepto más primordial de la obra, mientras que atendiendo al programa de la casa Sarabhai, resulta imprescindible la ocupación definida para sus hijos, preparada para acoger una familia nuclear al principio y, más tarde, una familia extensa a medida que los hijos formasen sus propias familias.

3. Tanto Gira como Gautam Sarabhai era arquitectos y fueron quieren lograron la presencia del maestro francosuizo en Ahmedabad. Fueron los responsables de respaldar conceptual y técnicamente la formulación y puesta en marcha del encargo para el museo municipal de Ahmedabad, el primero que obtuvo allí Le Corbusier.

Feminismo/s 32, diciembre 2018, pp. 65-99 


\section{LA LIMINALIDAD COMO ESTRATEGIA EN EL EMPLAZAMIENTO}

La ubicación de las tres viviendas parte de unas condiciones completamente distintas. Sin embargo, el interés de los tres casos surge de cómo la pieza de arquitectura se inserta en el contexto, tomando gran relevancia temas de liminalidad entre interior y exterior, tanto en contextos urbanos como naturales.

En el primer caso, la casa Schröder se ubica al final de una calle conformada por viviendas adosadas de ladrillo en Prins Hendriklaan, Utrecht, Holanda (figura 2). Sólo comparte una medianera y la fachada trasera se abre al campo. La fachada alineada con las casas vecinas responde a la escala de sus construcciones vecinas, mientras que la fachada lateral, paralela a la medianera, funciona como acceso principal a través de un pequeño jardín. De esta

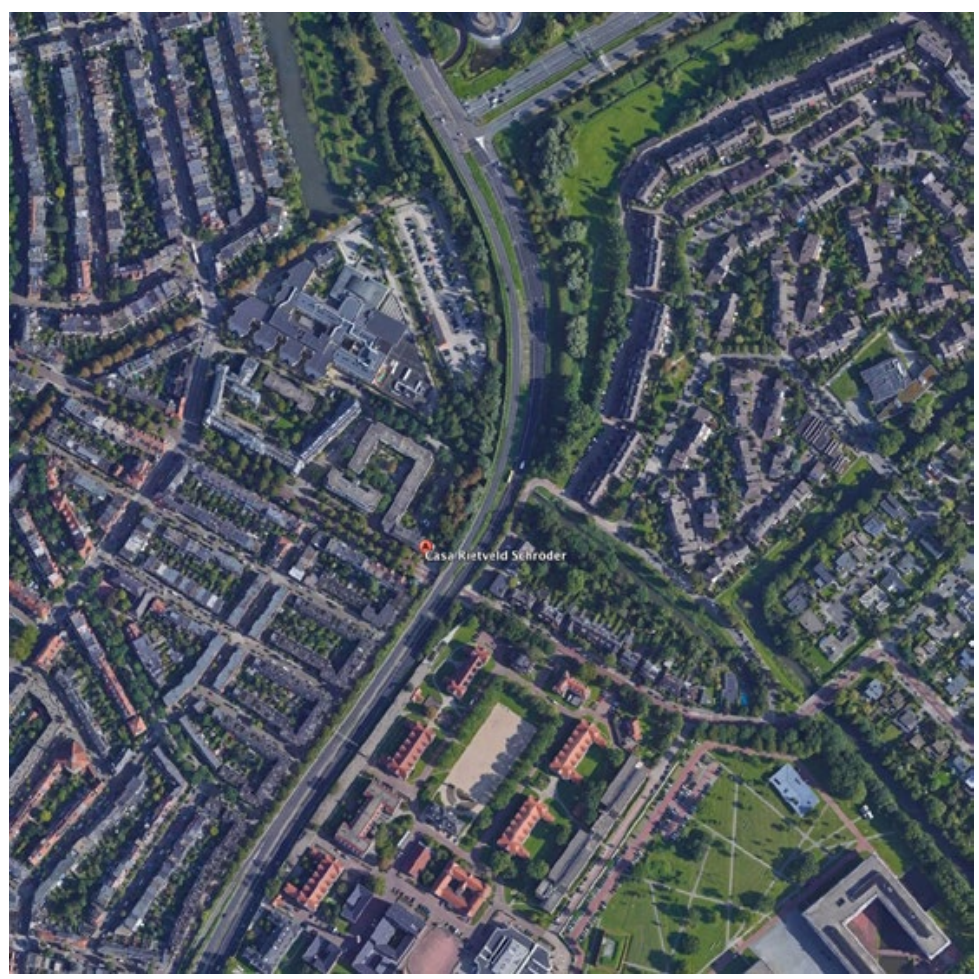

Figura 2.

Feminismo/s 32, diciembre 2018, pp. 65-99 
La reivindicación sostenible a través del encargo arquitectónico

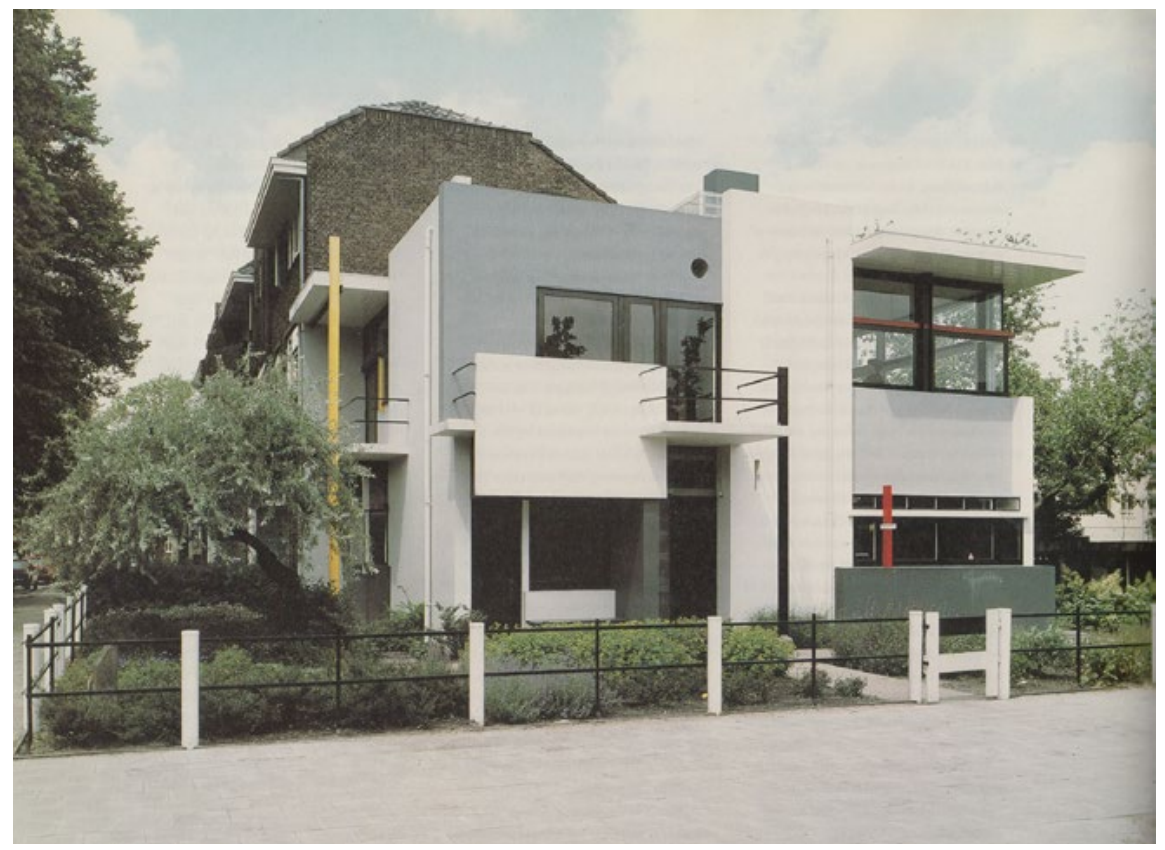

Figura 3.

manera, se consigue aislar la vivienda del entorno urbano (figura 3). Desde el interior, los grandes ventanales se abren a las vistas naturales, creando así un proyecto híbrido entre lo urbano y lo rural que intenta acercar a sus ocupantes al entorno natural. Las fachadas suponen una profunda ruptura con el contexto desde una perspectiva formal. Deja de ser un volumen con pequeños huecos que esconden el interior para pasar a ser un juego de planos con los que Rietveld modela el nivel de exposición con el exterior.

La casa Farnsworth, por su parte, se sitúa en un paraje natural (figura 4) alejado de la ciudad en Plano, Illinois (Estados Unidos). Distintos textos destacan que Edith y Mies acudieron en múltiples ocasiones a visitar la parcela. Se trata de una construcción en acero y vidrio donde el detalle constructivo y el archiconocido «less is more» se materializan para crear una obra imprescindible en la carrera de Mies y el Movimiento Moderno. Referirse al emplazamiento de la pieza arquitectónica implica considerar la solución en

Feminismo/s 32, diciembre 2018, pp. 65-99 


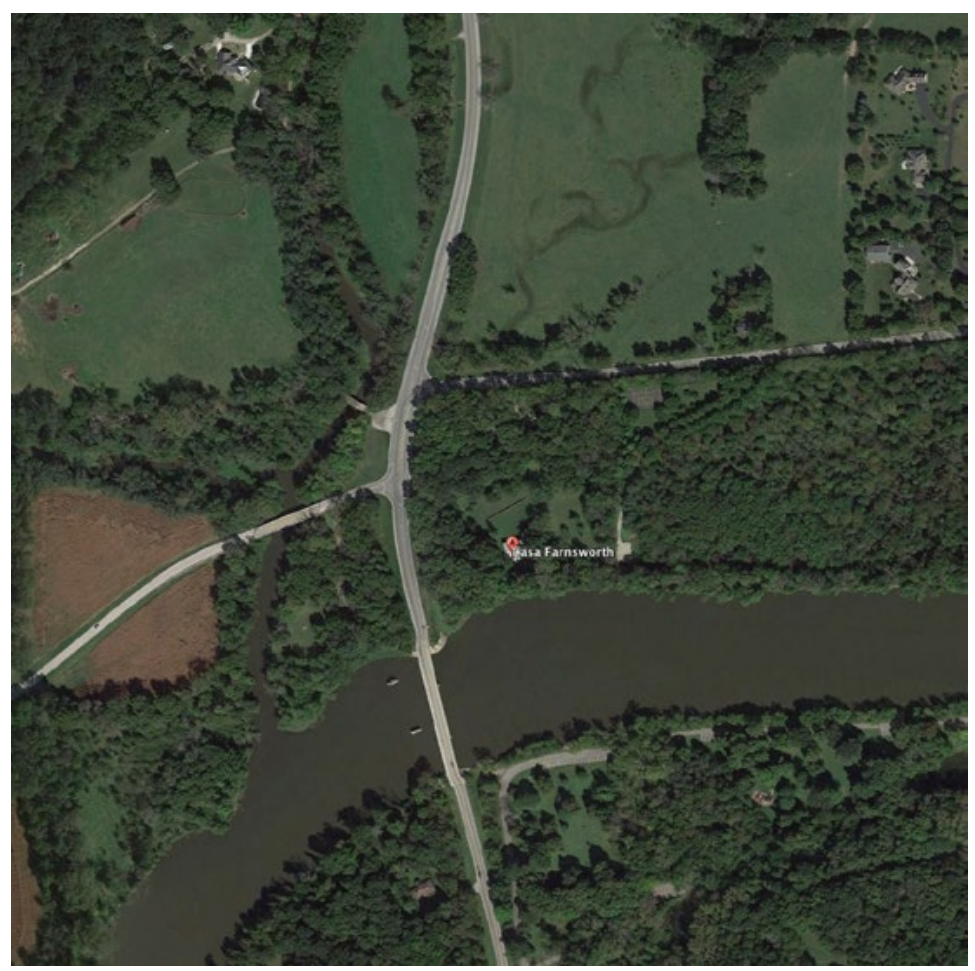

Figura 4.

fachada para delimitar el vínculo que se establece entre interior y exterior. $\mathrm{Y}$, en ese sentido, la transparencia radiográfica de los paños de vidrio serán definitorios dentro del discurso asociado a esta vivienda.

La primera acción de Mies se basó en replantear la vivienda en el lugar, para lo cual fue de suma importancia el gran árbol existente que se ubica en el lateral sur (figura 5). «El propio Mies estacó la casa, las cuatro esquinas del edificio y la terraza en relación con un gran árbol que fue una especie de punto focal» (Lambert 348). De esta manera, la vegetación caduca actúa como una segunda fachada, aportando sombra durante la época estival y permitiendo la entrada de luz en los meses más fríos.

Fritz Neumeyer ha analizado esta obra definiendo cómo los principios filosóficos, la razón y la forma prevalecían sobre el programa. Neumeyer

Feminismo/s 32, diciembre 2018, pp. 65-99 


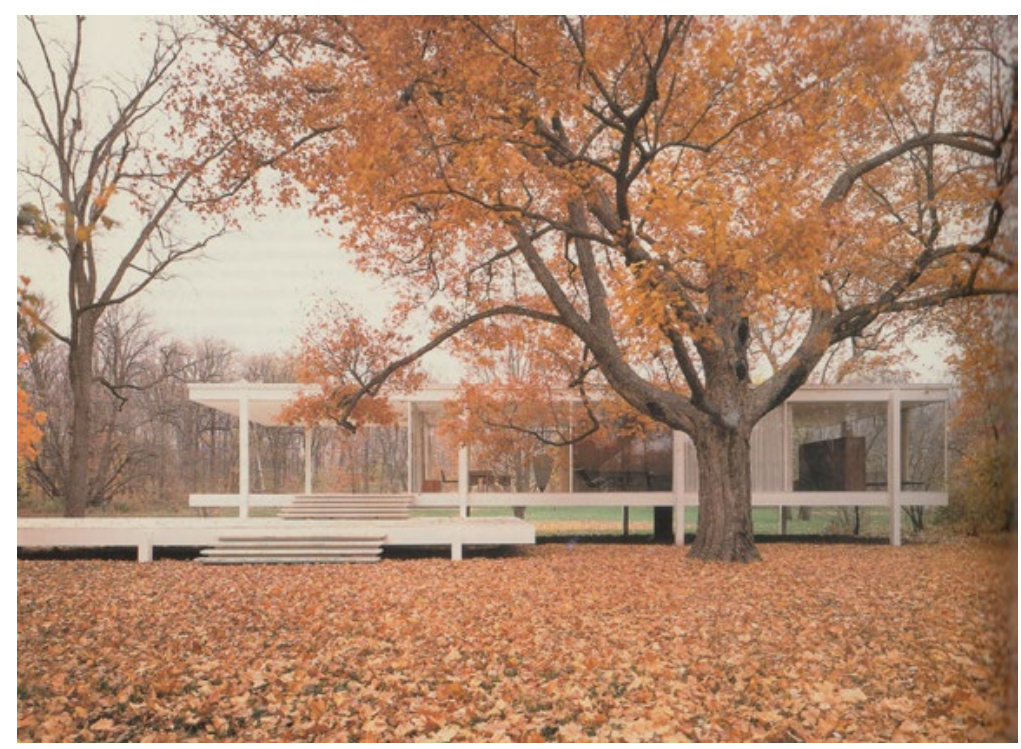

Figura 5.

alude a un proceso de vaciado del espacio en donde la pared interior consigue eliminar «hasta la última reliquia simbólica». Y de la misma manera ocurre algo similar con la estructura, «cada vez más hacia fuera», lo que evita pilares interiores y, junto al vidrio perimetral, consigue ampliar el espacio perceptivo (348). El peso de la abstracta base del discurso eleva el concepto de vivienda y la define como un «lugar de estancia contempladora» tal y como percibía Water Genzmer (Neumeyer 353). Una visión con un grado de utopía e idealización que bien puede ser responsable de todos los problemas derivados en cuanto a su habitabilidad. En cualquier caso, para Mies «cuando se mira la naturaleza a través de las ventanas de la Casa Farnsworth, adquiere un significado más profundo del que tiene cuando se está fuera, al aire libre. La naturaleza se realza al pasar a formar parte de un gran conjunto» (NorbergSchulz 615).

El tamaño y tipo de huecos de la casa Schröder y su ubicación con respecto a la envolvente conseguían modelar el nivel de exposición. En la casa Farnsworth, sin embargo, no existía un cerramiento que limitase la parcela, por lo que, según la solución definida, el nivel de exposición era realmente

Feminismo/s 32, diciembre 2018, pp. 65-99 
alto. No es de extrañar que Edith incluyese en fachadas cortinajes e incluso celosías para reforzar su privacidad, tal y como se puede comprobar en diversos documentos gráficos históricos de la vivienda.

En cuanto a la materialidad de la propuesta, Mies daba por supuesto que los temas referidos a la privacidad y la intimidad se solucionaban al ubicar la casa en un entorno natural inhabitado. Sin embargo, la sobreexposición continuada de alguna manera sí comprometía la vida privada de la propietaria y promotora de la casa.

La casa Sarabhai, por su parte, se ubica en un «retiro» propiedad de la familia (figura 6) situado en Shahibag, en Ahmedabad, India occidental. A diferencia de la Casa Farnsworth, la interacción y apertura al entorno circundante no implicaba una intromisión acuciada de la intimidad, pues se trataba



Figura 6.

Feminismo/s 32, diciembre 2018, pp. 65-99 
de una parcela con un perímetro cercado y existía una importante distancia con respecto a otras construcciones de la familia en el mismo enclave. Una suerte de oasis dentro de la ciudad de Ahmedabad.

El encargo se enmarcaba en un contexto en donde se daban dos hechos básicos: por una parte, se trataba de una familia de tradición jainista y la localización sería dentro de un recinto bellamente ajardinado propiedad de la familia, con un detallado diseño paisajístico y botánico. Las primeras decisiones tuvieron que ver con la ubicación de la vivienda dentro de la parcela teniendo en cuenta la inundabilidad de la misma y las especies vegetales que habría que retirar, así como el supuesto crecimiento de la vegetación que quedaría en el perímetro de la futura construcción. Aunque hubo distintas cartas durante el proceso de construcción de la vivienda tratando muy distintos temas, uno de los impuestos por la dueña de la vivienda era el de crear un recinto de entrada sin puerta alguna. Se quería crear una casa de «puertas abiertas» donde hubiese un fluir continuo entre el interior y el exterior de las personas, las aves, las corrientes de aire... se quería imprimir en el espacio el fluir continuo de lo natural (figura 7).



Figura 7.

Feminismo/s 32, diciembre 2018, pp. 65-99 
Esta idea casi abstracta de diseñar una casa sin puertas, impuesta por la promotora del proyecto, encajaba además con uno de los aspectos que más interesaba a Le Corbusier en sus trabajos en India: la adecuación al contexto climático. Es tal el nivel de relación entre interior y exterior, que lo ambiguo de la propuesta obliga a referirse a la organización espacial de la vivienda para hacer referencia a su implantación en el contexto. El proyecto resultó ser la vivienda tipo «Monol» más evolucionada de toda la carrera de Le Corbusier. Diez espacios abovedados yuxtapuestos de una importante profundidad modelan un espacio arquitectónico definido por el plano en sombra con un alto grado de habitabilidad gracias a la porosidad de la propuesta, expuesta a la ventilación cruzada de manera continua. En fachada, Le Corbusier define verandas, bien entendidas como espacios de transición (figura 8), en donde la solución constructiva del plano de fachada retranqueada convierte estos elementos en dispositivos versátiles capaces de adaptarse a las necesidades derivadas del clima (Futagawa y Futagawa 6). En la planta superior, las verandas



Figura 8.

Feminismo/s 32, diciembre 2018, pp. 65-99 
y jardineras funcionan también como elementos mediadores entre interior y exterior. Además, Le Corbusier preparó estos espacios de transición para ser ocupados durante las noches más calurosas.

El encargo inicial de Manorama Sarabhai de construir respetando absolutamente el entorno natural, además de su obsesión por eliminar las puertas de paso, junto con este entendimiento de los límites del propio arquitecto, implicaban una postura sostenible. Además, esta postura se reforzaba con el conocimiento de la arquitectura vernácula y atendía a las limitaciones tecnológicas del lugar. Aunque utilizó hormigón armado, también empleó ladrillo cocido en obra; dos materiales de fácil disponibilidad que además reducían la repercusión en el entorno disponiendo de los materiales del lugar.

Otro aspecto de relevancia es la cubierta vegetal entendida como un elemento de protección y aislamiento frente al duro clima (figura 9). La

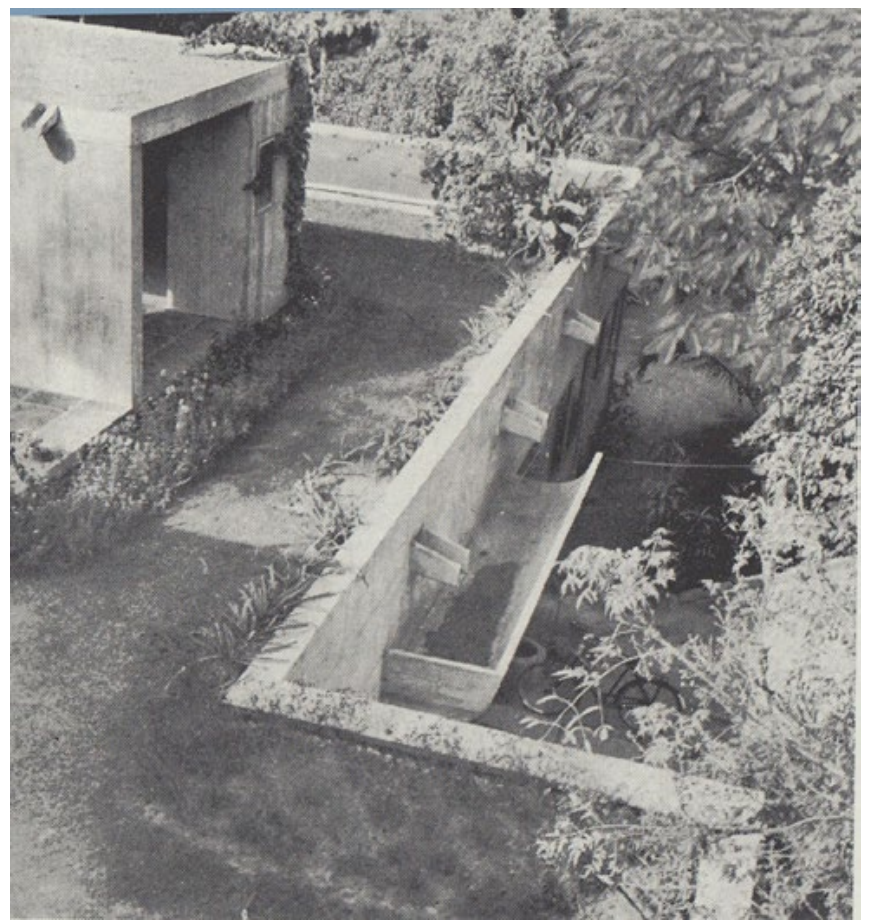

Figura 9.

Feminismo/s 32, diciembre 2018, pp. 65-99 
solución estructural de bóvedas permitía una mejor derivación de las cargas y esta profunda capa de tierra incluía canales de agua que la atravesaban. La solución no sólo activaba el uso de la azotea, sino que también conseguía un aislamiento muy superior comparado con otras soluciones basadas en la creación de pérgolas de hormigón, como por ejemplo en la casa Shodhan. Además de «devolver» a la naturaleza la porción de terreno ocupado por la vivienda, se estaban preparando los niveles elevados para ser utilizados en las noches más calurosas permitiendo en una misma construcción crear dispositivos donde mantener una cierta autonomía dentro de un conjunto interrelacionado.

\section{INNOVACIÓN A TRAVÉS DE LA PROPUESTA ESPACIAL}

La señora Schöder tomó como punto de partida la concepción espacial de la vivienda de la típica familia burguesa, para contestarla y plantear innovaciones en la ordenación de los espacios y, por lo tanto, en las relaciones familiares que en ellos se desarrollan. La acusada compartimentación de las estancias de ese modelo tradicional reflejaba una jerarquía y una contención, así como una semántica implícita, un orden moral, que Truss quería eliminar. Frente a este modelo, creó junto a Rietveld un espacio fluido y versátil capaz de permitir un tipo de relaciones dentro del núcleo familiar mucho más abiertas y equitativas. De esta manera, la casa Schröder funcionaría como un medio espacial capaz de estimular a la gente a vivir en él, e incluso pensar de distinta forma. De alguna manera, la vivienda funcionó como un laboratorio donde ellos mismos, Schröder y Rietveld, experimentaron todos estos temas.

El eje central del discurso de Truss Schröder se apoyaba en potenciar la vida familiar según ella la entendía, es decir, una configuración espacial compartida por madre e hijos creando una atmósfera dinámica donde también se propiciase el contacto entre niños y adultos. Quería hacerles partícipes de los debates que allí se darían y, por lo tanto, potenciar la idea de convertir la convivencia en una experiencia estimulante.

Cuando Truss se refiere al proceso creativo de la vivienda, explica cómo lo primero que hicieron fue replantear en la parcela una distribución preliminar de manera colectiva incluyendo a sus hijos. Ella no quería vivir en

Feminismo/s 32, diciembre 2018, pp. 65-99 


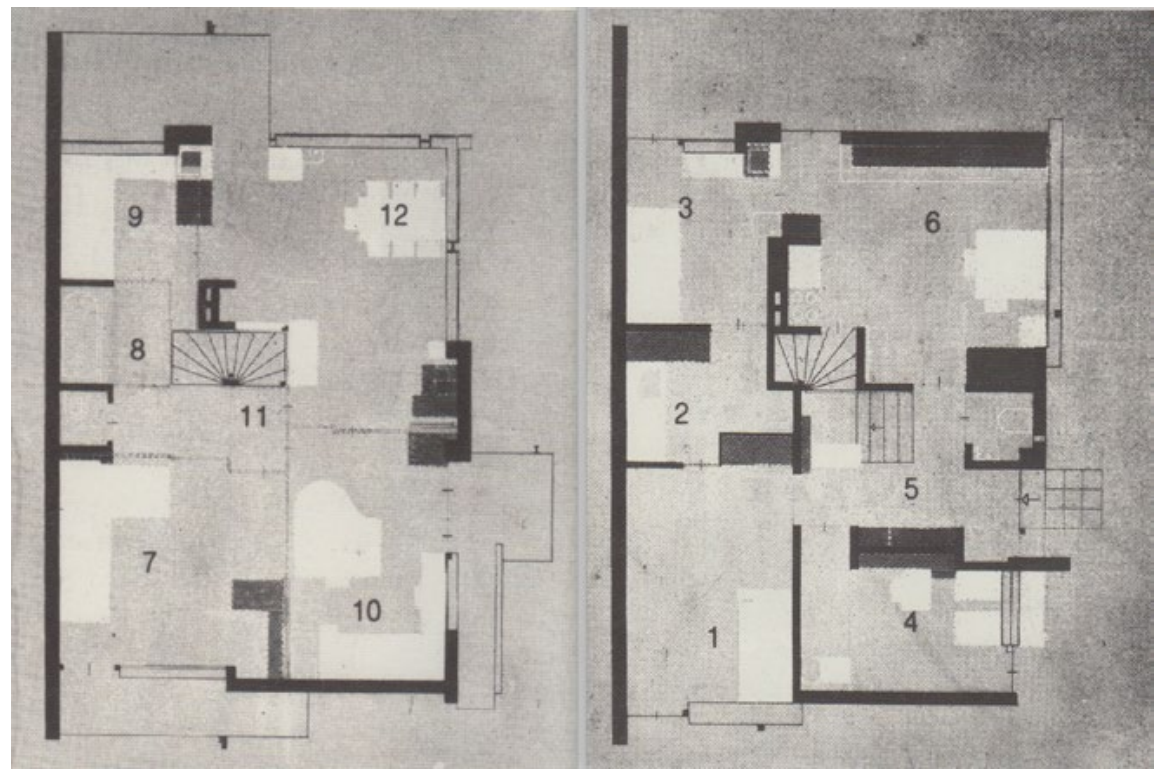

Figura 10.

la planta baja, lo cual fue aplaudido por Rietveld, más teniendo en cuenta que las mejores vistas se conseguían desde los niveles superiores. Por lo tanto, la primera decisión se basó en invertir la organización espacial por niveles. Las zonas estanciales se ubican en la planta alta junto a los dormitorios, de modo que los espacios más privados conseguirían urbanizarse en gran medida. Ella misma reconoció que hubo muchos desencuentros con su difunto marido en cuanto a la manera de educar a sus hijos (Friedman, Your place or mine? 74).

La casa consta de dos alturas (figura 10). En planta baja se organiza un estudio, una biblioteca, un espacio de trabajo que originalmente había sido la habitación de servicio, y una cocina con un comedor. En la planta superior se ubicaba un dormitorio para chicas, otro para el único hijo varón, un tercer dormitorio para Truss, así como un espacio de salón y comedor. Mientras que los espacios en planta baja tienen una rígida estructura espacial, en la planta superior distintos mecanismos de paredes deslizables permiten

Feminismo/s 32, diciembre 2018, pp. 65-99 
La reivindicación sostenible a través del encargo arquitectónico

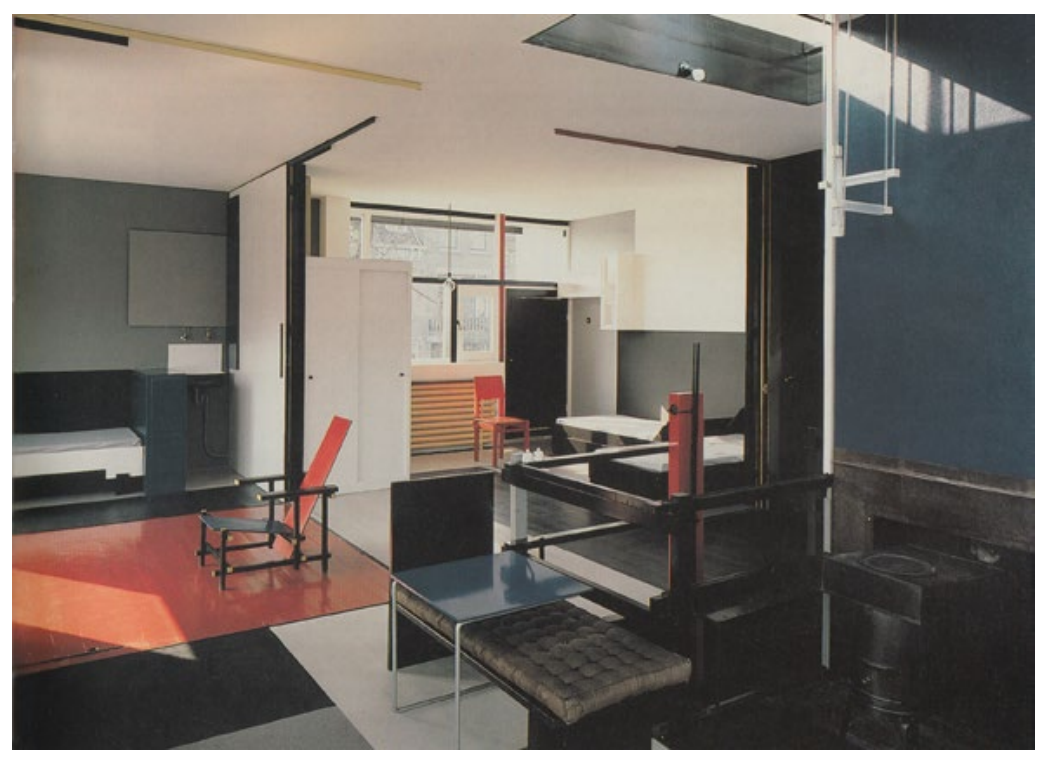

Figura 11.

compartimentarlo o crear un gran espacio común (figura 11). «Cuando Rietveld había hecho un croquis de las habitaciones, pregunté ¿'Se pueden quitar estas paredes también?' A lo cual él respondió ‘Con mucho gusto, ¡Fuera esas paredes!’» (Friedman, Your place or mine? 76).

Aunque el dormitorio de Truss no disponía de paredes móviles, su reducido tamaño buscaba animar la vida en común con sus hijos. El mobiliario también jugaba un papel imprescindible a la hora de definir las actividades que allí se desarrollaban, creando por ejemplo mesas de trabajo en las zonas comunes (figura 12). Aunque esta vida comunal podría incomodar a sus ocupantes en términos de privacidad e intimidad, los espacios en planta baja fueron capaces de suplir dichas carencias.

Las líneas dedicadas en el presente capítulo se han centrado en las aportaciones de Truss Schröder gracias a su visión personal sobre las teorías en cuanto al desarrollo de sus hijos, el espacio abierto y la vida de la familia moderna. Sin embargo, no se puede obviar el papel de Rietveld en las soluciones de la vivienda, su capacidad espacial y su lenguaje personal.

Feminismo/s 32, diciembre 2018, pp. 65-99 


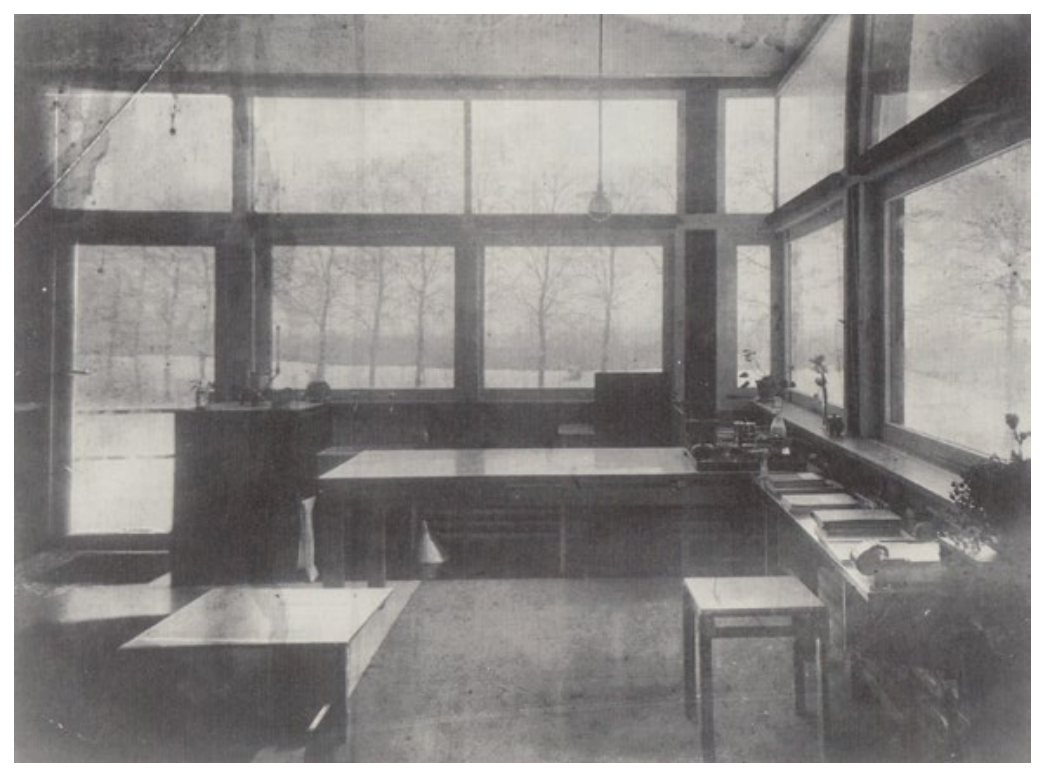

Figura 12.

En el caso de la vivienda diseñada por Mies van der Rohe para Edith Farnsworth, a la hora de plantearse la configuración de los espacios, se da una condición de base imprescindible a tener en cuenta, la ausencia de hijos. Edith, soltera e independiente, tenía un perfil de cliente que interesaba sobremanera a Mies por su cultura, su estatus social y económico, pero sobre todo porque su situación familiar le permitía experimentar una nueva tipología doméstica.

La organización de la vivienda se plantea como una secuencia que traslada al usuario desde el contacto con el exterior directo hasta el interior oculto de los baños (figura 13). Al porche de acceso precede una plataforma descubierta que inicia una transición organizada en distintas fases. El programa de la vivienda se ubica en el segundo nivel, a la misma altura que el porche de acceso, y su perímetro se completa con una fachada de vidrio en sus cuatro caras. Un elemento central y aislado articula los distintos recintos espaciales alrededor de este, liberando el perímetro; una cocina, un dormitorio y zonas comunes. Ese elemento central acabado en madera aloja las instalaciones,

Feminismo/s 32, diciembre 2018, pp. 65-99 


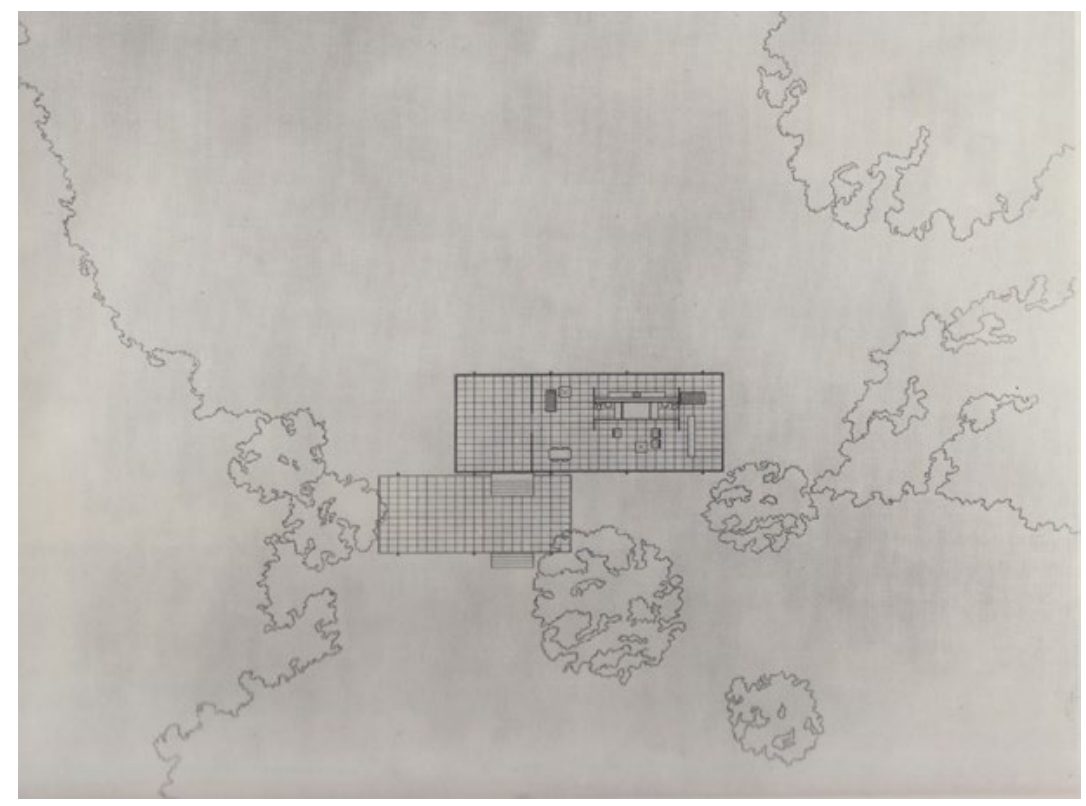

Figura 13.

baños, muebles de cocina y chimenea. Por lo tanto, se trata de una vivienda con un único dormitorio $y$, en este caso, ningún tabique ofrece la opción momentánea de aislamiento. Su definición se articula mediante el mencionado núcleo y los muebles juegan un papel primordial en la definición de los distintos ámbitos (figura 14). El grado máximo de intimidad ni siquiera reside en el dormitorio como habitualmente ocurre en las viviendas occidentales, sino en los baños.

De alguna manera, la aproximación de Mies a este proyecto supone la resolución de un problema de tipo. De hecho, este caso de estudio despertó el interés del público general y especializado animando un debate sin precedentes sobre la domesticidad americana, la sexualidad y la política.

La vivienda como tal encierra un significado conceptual donde el ejercicio de abstracción de su solución formal implica un cuestionamiento directo de su modo de ocupación, de manera que los patrones de comportamiento de su ocupante toman un peso específico. 
La reivindicación sostenible a través del encargo arquitectónico

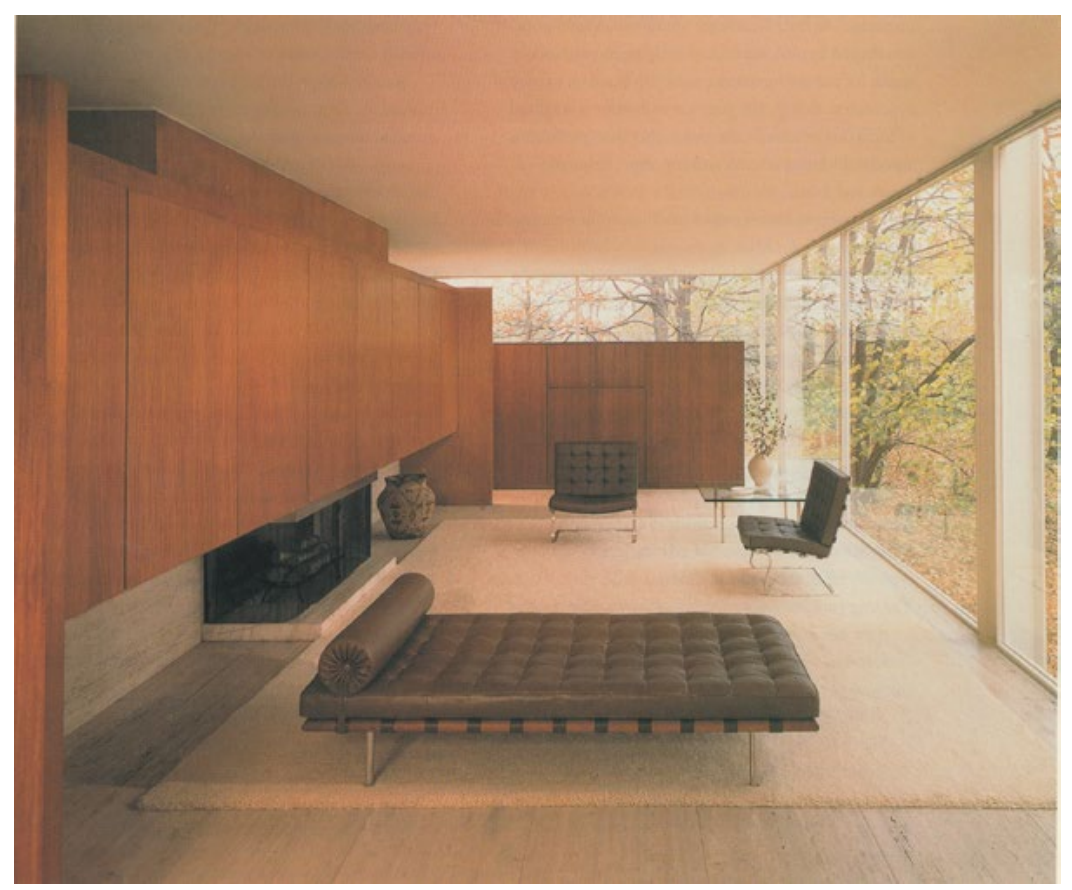

Figura 14.

Lo interesante resulta ser cómo el proyecto abrió un debate nacional sobre la familia, cuestiones de género y el control de las apariencias, particularmente en el entorno doméstico. Al fin y al cabo, la propuesta de Mies hacía tambalear la tradición americana. Incluso la modestia servía como argumento para reforzar el argumento de la privacidad. Las críticas de Edith incluían la carencia de espacios para invitados, o el baño oculto y de reducidas dimensiones que para muchos representaba la represión del cuerpo femenino. Se negó a que Mies diseñase el mobiliario de la casa y criticó en diversos medios que Mies no tenía en cuenta algo de especial relevancia para ella y es que su casa debía representarla como persona.

Si en el caso de Manorama Sarabhai y Le Corbusier, las exigencias de la una concordaban con los intereses del otro en cuanto a configurar los espacios de tal manera que se integrasen con naturalidad en el entorno, en el caso de

Feminismo/s 32, diciembre 2018, pp. 65-99 
la casa Farnsworth, los puntos de vista de arquitecto y promotora enseguida se distanciaron. De hecho, Edith Farnsworth hizo público en multitud de ocasiones su disconformidad con la vivienda, aunque vivió en ella durante 21 años (Gray 2000 26). La privacidad fue sin duda uno de los asuntos más problemáticos para la dueña, quien sufrió en primera persona la curiosidad de todos aquellos que se desplazaban hasta el apartado enclave para visitar la famosa casa.

En la casa Sarabhai el programa se fracciona en dos edificios; uno ocupado por la villa principal y otro reservado al servicio. Al mismo tiempo, el edificio principal debía estar dividido en dos zonas; una destinada a la Señora Sarabhai y su hijo menor y la otra exclusivamente para su primogénito (figura 15). El

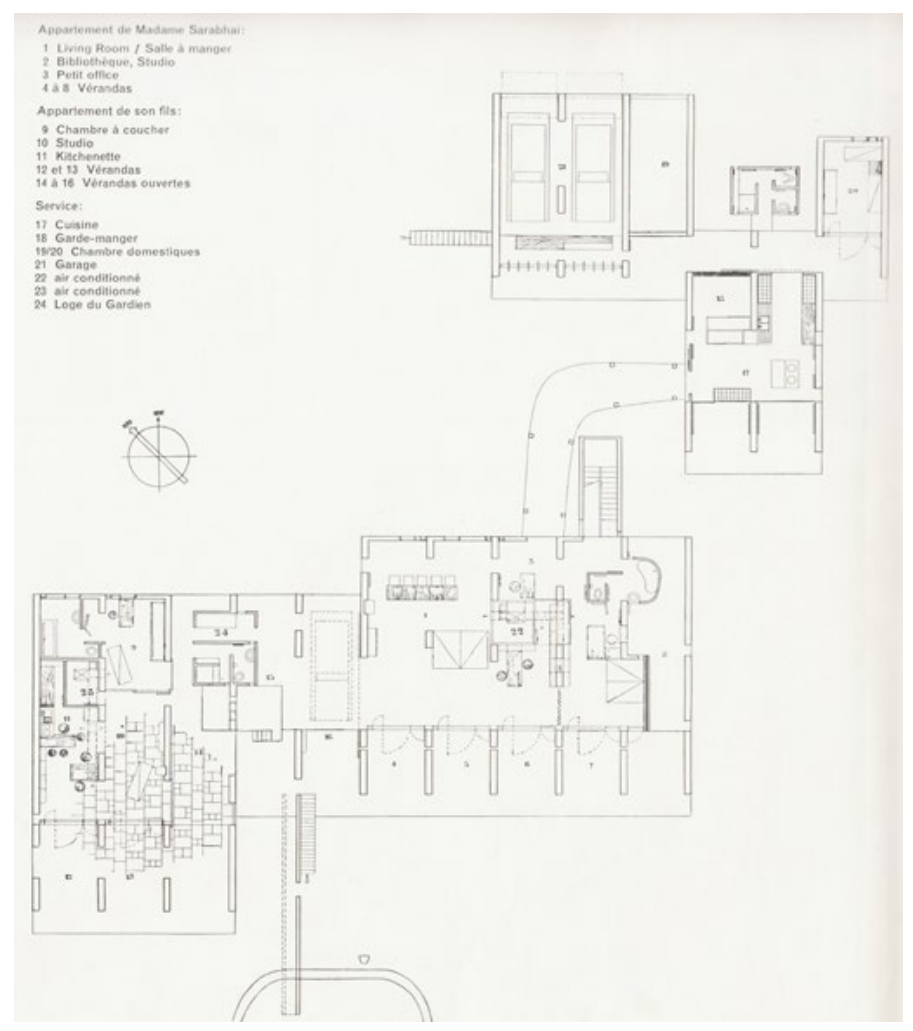

Figura 15.

Feminismo/s 32, diciembre 2018, pp. 65-99 
único elemento que se hace presente de una manera ciertamente exhibicionista es el tobogán antes referido que desciende desde la cubierta, el cual también sirve para delimitar las dos zonas importantes del edificio principal, relacionadas por dos unidades abovedadas sin puerta alguna en fachada, funcionando el elemento formal de unidades abovedadas como una superestructura que relaciona las distintas partes, las cuales al mismo tiempo tienen un alto grado de independencia.

Las mencionadas bóvedas tabicadas descansan sobre vigas de hormigón que apoyan a su vez sobre muros de ladrillo, los cuales permiten articular las distintas estancias. La longitudinalidad derivada de esta solución formal se deshace gracias a las vistas diagonales que atraviesan la casa, para lo cual fue imprescindible la definición de la tabiquería interior de ladrillo (figura 16). En lugar de plantearse como una construcción de habitáculos, estos espacios abovedados disponen de unas paredes móviles correderas que adaptaban la

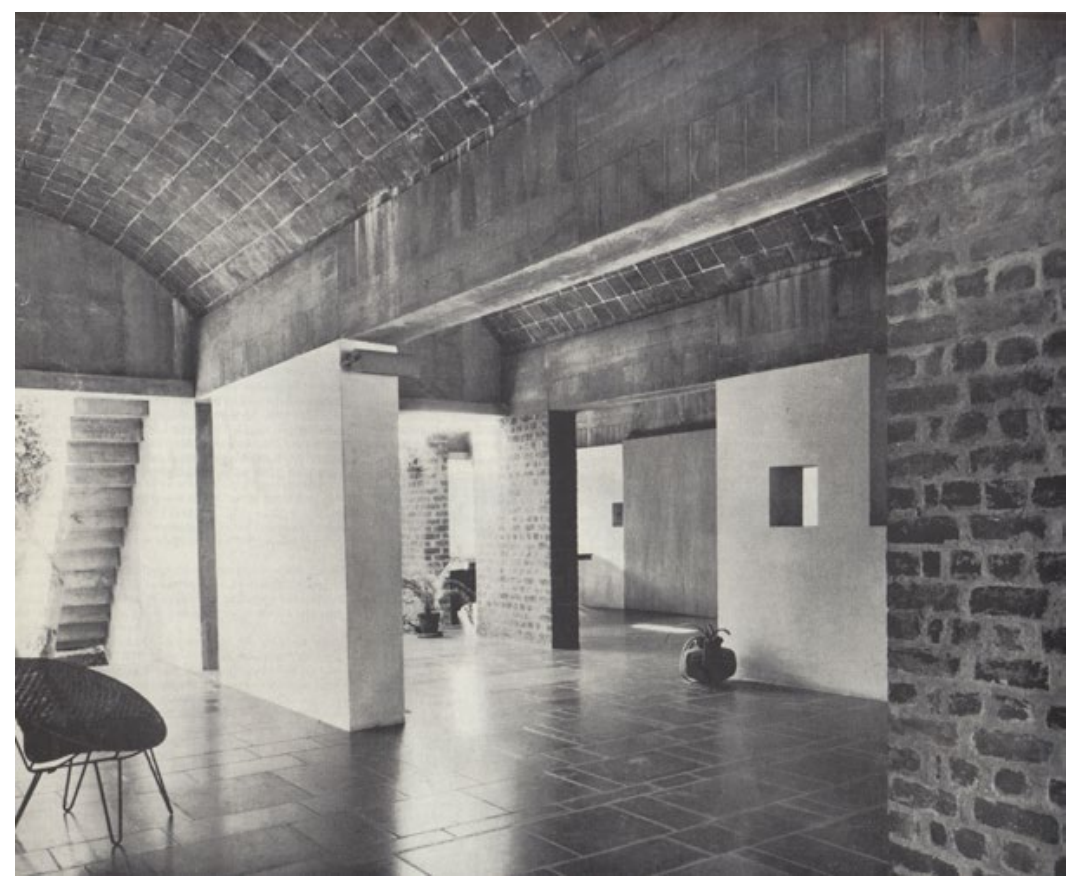

Figura 16.

Feminismo/s 32, diciembre 2018, pp. 65-99 
La reivindicación sostenible a través del encargo arquitectónico

vivienda a las distintas necesidades que surgen; la flexibilidad espacial fue también uno de los requisitos exigidos para la vivienda. Frampton recoge una cita de Sunand Prasad donde describe cómo la casa ha sufrido diversas modificaciones a lo largo de los años según las necesidades de sus habitantes «sin que todo ello modificara de manera significativa su carácter» (Frampton 194). El orden establecido por los espacios seriados y permanentes son los responsables de conferir el citado carácter de la vivienda, permitiendo que acciones de menor orden no repercutan en los principios más básicos que definen la propuesta.

En cuanto a la configuración de los espacios, si se comparan los tres ejemplos expuestos, en el caso de Sarabhai y Schröder quedaron mucho más satisfechas que Farnsworth. En esos dos primeros casos, la relación entre la madre y los hijos se traduce en una propuesta espacial que se adapta a dicha situación. Sin embargo, en la casa Farnsworth, las ideas del arquitecto se impusieron por encima de las necesidades de la cliente. Mies argumentó su solución de diversas maneras, pero sin ofrecer una solución convincente en términos de privacidad para Edith.

\section{CONCLUSIONES}

La modernidad de las tres viviendas se construye atendiendo a perspectivas que parten de visiones particulares como la consideración del entorno, su forma de relación desde el interior de la vivienda o el entendimiento de los límites dentro de esta, apoyándose siempre en el uso de sistemas constructivos que se ponen al servicio de la dimensión más abstracta del proyecto. Sin embargo, a estos aspectos comunes en la buena arquitectura, hay que sumar innovaciones que se explican desde una perspectiva de género. No sólo se trata de tres viviendas promovidas por mujeres, sino que se trata de mujeres muy distintas entre sí y con situaciones familiares diversas.

Truss Schröder, Edith Farnsworth y Manorama Sarabhai han contribuido al mecenazgo femenino con la promoción de tres obras marcadas por la personalidad de cada una de ellas y que se han convertido en referentes de la arquitectura residencial moderna. A partir de ahí, interesa subrayar en estas conclusiones los puntos de encuentro que evidencian cómo las novedades espaciales, motivadas por la intervención de estas tres mujeres, pueden entenderse como soluciones que ponen en duda el orden establecido y acercan a

Feminismo/s 32, diciembre 2018, pp. 65-99 
La reivindicación sostenible a través del encargo arquitectónico

nuevas configuraciones que ayudan a entender hasta qué punto el diseño de una vivienda influye en aspectos de la igualdad de género.

Además de sus perfiles como mujeres cultas con una consciencia plausible sobre el mundo moderno y la necesidad de reconsiderar el rol de la mujer, se puede destacar un denominador común en todas estas viviendas que se basa en deshacer el par dicotómico dentro-fuera, el cual lleva asociado una semántica vinculada a la connotación de lo masculino y lo femenino como conceptos antagónicos. Las tres propuestas, en mayor o menor medida, hacen partícipe al entorno exterior del interior de la vivienda. La casa Sarabhai de manera literal busca la fusión física con el entorno natural, la Farnsworth eleva esa interacción a través de la contemplación y la casa Schröder, además, busca urbanizar la dimensión más privada de la vivienda incorporando la vida social como una variable más en la definición del programa residencial.

En términos de liminalidad, se alteran las rígidas fronteras entre interior y exterior, de modo que aquello que tiene que ver con lo privado no marche en paralelo a lo público y lo natural. Incluso en el interior del espacio de vivienda, la rígida compartimentación de los espacios más privados, los dormitorios, hacen uso de paredes móviles creando espacios versátiles que se adaptan a las necesidades de sus ocupantes. De esta manera, se reconfigura el grado máximo de intimidad dentro de la casa, lo que incide directamente en los modos de vida heredados de la sociedad capitalista basada en la estricta individualidad. Así, estas nuevas perspectivas consiguen deshacer una estricta jerarquía y la vivienda ofrece múltiples posibilidades en cuanto a interacción social, dentro del núcleo familiar y con respecto a usuarios ajenos transitorios.

Deshaciendo el peso del límite estricto y, por lo tanto, el binomio interior-exterior, se crean límites difusos entre las clásicas «esferas separadas» de lo masculino y lo femenino. La ambigüedad y la no definición de entes espaciales abruptos consiguen definir una propuesta que anima una visión más unitaria y universal entre hombres y mujeres, una suerte de sostenibilidad social en el más amplio sentido de la palabra. Urbanizar el espacio interior mediante operaciones basadas en deshacer los límites consigue anular la desvinculación con el entorno natural, tomando una mayor consciencia de pertenencia a un todo (persona-familia-sociedad-entorno).

Esa ambigüedad incluso se puede identificar desde el discurso propio del arquitecto a nivel de lenguaje. Referido a Le Corbusier, Von Moss sostiene

Feminismo/s 32, diciembre 2018, pp. 65-99 
que la casa Sarabhai es la culminación de una de las corrientes antitéticas que evolucionan a lo largo de su carrera: la architecture femelle, que comienza en 1919 con las casas Monol, en oposición a la architecture mâle, iniciada con la casa Citrohan (1922) y finalizada con la Villa Shodhan (1951) (160-165). Esta clasificación, además de atender a distintas variables, se sustenta en la solución formal de sus elementos. Le Corbusier vinculaba las líneas rectas a lo masculino y las soluciones curvas (espacios abovedados de la casa Sarabhai) a lo femenino. Más allá del análisis formal de la obra del arquitecto, hay que recordar que en la casa Sarabhai concretamente, fue Manorama quien exigió al arquitecto la ocultación de las bóvedas al exterior «por su imagen industrial» (Gans 209). Le Corbusier combinó un sistema arquitrabado en el exterior con un interior abovedado a partir de las indicaciones de su clienta. La mencionada ambigüedad surge de la interacción entre cliente y arquitecto y, por lo tanto, incluso el par dicotómico masculino-femenino desde una perspectiva de lenguaje deshace la estricta clasificación.

No es intención de este artículo en ningún caso ignorar la importancia de los arquitectos citados, pero sí recuperar la figura de sus clientes cuya intervención es fundamental para entender las obras analizadas.

Le Corbusier es, sin duda alguna, quien consigue incorporar la sostenibilidad medioambiental de manera más evidente desde una perspectiva arquitectónica-constructiva. Además de fusionar de manera literal interior y exterior, lo cual también viene facilitado por el contexto climático indio, su atención al entorno anima al uso de materiales tradicionales como el ladrillo, sin negar las aportaciones de sistemas constructivos modernos. Pero también importa soluciones de otros contextos que presuponía positivos, como las bóvedas tabicadas. La lámina de agua, las acequias o la cubierta vegetal y su extraordinaria capacidad de aislamiento, también se incluyeron en la propuesta dando forma a un conjunto que se autodefine moderno siendo sostenible en su más amplio sentido de la palabra. Una gran aportación, más si se tiene en cuenta el contexto de pobreza de la India. Curtis rescata una frase de Le Corbusier que refleja a la perfección la postura adoptada por el arquitecto: «Construyendo de una manera moderna, uno ha encontrado armonía con el contraste, el clima y la tradición» (212).

Las tres viviendas analizadas son imagen en mayor o menor medida de sus mecenas, mujeres cuyo legado a día de hoy sigue siendo una fuente

Feminismo/s 32, diciembre 2018, pp. 65-99 
La reivindicación sostenible a través del encargo arquitectónico

inestimable de inspiración y aprendizaje. Los tres proyectos evidencian cómo a través de la arquitectura se pueden modelar los escenarios en los que se desarrolla la vida y que no son otra cosa que un reflejo de la sociedad que los habita. Tomando consciencia de los significados implícitos de los espacios que habitamos, será posible utilizar la arquitectura en aras de los valores que persigue nuestra sociedad y no en el sentido contrario. Necesariamente, la arquitectura se debe considerar desde una perspectiva de género y una dimensión sostenible. No por capricho, sino porque, como se muestra en este artículo, explican muchos de los aspectos de las grandes obras de la arquitectura.

\section{REFERENCIAS BIBLIOGRÁFICAS}

Barthes, Roland. La semiología. Buenos Aires: Editorial Tiempo Contemporáneo, 1970.

Badovici, Jean. «Maison à Utrech par T. Schraeder et G. Rietveld». L'architecture vivante 6 (1925): 28-29.

Caballero Galván, Javier. «Los criterios de diseño arquitectónico de la vivienda moderna desde la perspectiva de género». Debate Feminista 51 (2016): 36-49.

Castillo, Greg. «Design Pedagogy Enters the Cold War». Journal of Architectural Education, Vol. 57, 4 (2004): 10-18.

Combalía, Victoria. Musas, mecenas y amantes. Mujeres en torno al surrealismo. Barcelona: Editorial Elba, 2016.

Curtis, William. Le Corbusier: Ideas y Formas. Madrid: Hermann Blume, 1987.

Del Valle, Teresa. «El espacio y el tiempo en las relaciones de género». Kobie (Serie Antropología Cultural) 5 (1991): 223-236.

Fernández Salas, Elena. «Farnsworth - Mies: Binomios creadores necesarios para la reformulación del espacio doméstico». Pretextes D’Arquitectura 4 (2012): 6-7.

Frampton, Kenneth. Le Corbusier. Londres: Thames \& Hudson, 2001.

Friedman, Alice T. «Your place or mine? The client's contribution to domestic architecture». Women's places: Architecture and Design 1860-1960. Ed. Brenda Martin y Penny Sparke. Londres: London Routledge, 2003. 69-87.

- Women and the Making of the Modern House: A Social and Architectural History. Nueva York: Harry N. Abrams, 1998.

Futagawa, Yoshio y Yukio Futagawa. Le Corbusier: Sarabhai House, Ahmedabad, India, 1951-55. Tokio: A.D.A. Edita, 2011. 
La reivindicación sostenible a través del encargo arquitectónico

Gans, Deborah. The Le Corbusier guide. Princeton: Architectural Press, 1987.

García García, Rafael. (2011). «La casa Schröder: El arquitecto, la casa, interiorismo y propietarios». Descubrir El Arte. Separata-libro Casas Con Arte 7147 Vol. 13 (2011): 4-29.

García González, Andrea, Vicente Mas Llorens y José Santatecla Fayos. «La Villa Sarabhai. La riqueza de lo ambiguo». Actas de Congreso internacional: Le Corbusier, 50 years later. Valencia: Universidad Politécnica de Valencia, 2015. Gray, Julie. «If mies wall could talk». Interiors 159, 7 (2000): 26.

Gray, Paul. «The Common Sense Book of Baby and Child Care». Time 151.22 (1998): 108.

Lawrence, Cynthia. Women and Art in Early Modern Europe: Patrons, Collectors, and Connoisseurs. Pensilvania: Pennsylvania State Univ. Press, 1997.

Lambert, Phyllis. Mies in America. Nueva York: Whitney Museum of American Art, 2001.

Moisset, Inés. «Cien arquitectas en Wikipedia». Dearq 20 (2017): 20-27.

Neumeyer, Fritz. Mies van der Rohe. La palabra sin artificio. Reflexiones sobre arquitectura, 1922-1968. Madrid: Croquis, 1995.

Norberg-Schulz, Christian. «Ein Gespräch mit Mies van der Rohe». Baukunst und Werkform 11 (1956): 615.

Rietveld, Gerrit, Marijke Küper, Wim Quist y Hans Ibelings. Casas = houses. Barcelona: Gustavo Gili, 2006.

Samuel, Flora. Le Corbusier: Architect and feminist. Chichester: Wiley Academy, 2004.

Sánchez Pérez, Francisco. La liturgia del espacio. Madrid: Nerea, 1990.

Santos Pedrosa, Patricia. "Women architects in Portugal, a long and winding road». ArquitectAS: Redefiniendo la profesión. Nuria Álvarez Lombardero. Sevilla: Universidad de Sevilla, 2014. 99-112.

Vandenberg, Maritz. Farnsworth house: Ludwig Mies van der Rohe. Londres: Phaidon, 2003.

Von Moss, Stanislaus. Le Corbusier. Barcelona: Editorial Lumen, 1977.

\section{FILMOGRAFÍA}

Rewal, Manu y Fundación ARQUIA. Le Corbusier en la India: Ahmedabad y Chandigarh [Documental] (2000). http://fundacion.arquia.es/es/mediateca/ filmoteca/Documentales/Detalle/68? seccion=DOC\&palabra=corbusier $\&$ catalogo $=1$

Feminismo/s 32, diciembre 2018, pp. 65-99 